\title{
The Overall Measures to Build the World- Class Universities and the World-Class Subjects
}

\author{
Li Xiaolong \\ Department of Costume Engineering \\ Jiangxi Institute of Fashion Technology \\ Nanchang, Jiangxi \\ E-mail:576816683@qq.com
}

\begin{abstract}
It is a great strategic decision to build the worldclass universities and the world-class subjects which had been made by the Party Central Committee and the State Council. It will have very important significance for promoting the education development level of our country, strengthening the core competitiveness of our country and establishing the lasting development basis. For many years, through the implementation and construction of the 211 project, the 985 project and the creation platforms of the superior subjects and the key subject projects with the characters, a group of key universities and key subjects had made great progress, driving the comprehensive level promotion of higher education and making great contribution to the continual and healthy development of the society.
\end{abstract}

Keywords-World-Class Universities; World-Class Subjects; the Overall Measures; Construction; Build

\section{INTRODUCTION}

\section{A. Guiding Ideology}

In order to realize the struggling goal of two hundred years and provide a powerful support for Chinese Dream about Chinese nation' s great rejuvenation, we must hold the great banner of socialism with Chinese characteristics, put Deng Xiaoping Theory, the important thought of Three Represents and the Scientific Development as its guide, seriously carry out the spirit of the Party' s 18th National Congress and the second, the third and the fourth plenary session of the 18th central committee of the communist, thoroughly implement the spirit of s series of speeches the president $\mathrm{Xi}$ Jinping, accord to the strategy layout of the four comprehension and the decision deployment of the Party Central Committee and the State Council, insist the core of Chinese characteristics and the world-class, take high moral values establishment and people cultivation as the basis, put supporting creation Drive development strategy and serving the economy society development as the lead, accelerate to build a series of world-class universities and world-class subjects and improve the comprehensive influence and international competition of higher education.

How to insist Chinese characteristic and world-class? We must implement the education policy of the Party fully; insist the social operation-school direction, and enhance the guide of the party to the universities; take root in China and comply with laws of higher education; inherit the excellent traditional culture of China with creation; explore positively the road to build the world-class and the world-class subjects with Chinese characteristics; let China become the participant and the pusher of the world higher education' s reform and development; cultivate the constructors and the successors of the social cause with Chinese characteristics to serve the social modern construction and the people better [1].

\section{B. Basic Principle}

Insist on the world-class as the target. Lead and support the excellent universities and subjects which had achieved a great progress aim at the world-class. The university should converge high quality resources; cultivate the world-class talents; product the world-class achievement, accelerate to achieve the world-class.

Insist on the subjects as the basis. Lead and support the universities to optimize the subject structure; compact the subject development direction; highlight the subject construction importance; create the subject organization model; make a number of subjects summit; drive the universities to use the advantage and operate with its characteristics.

Insist on the performance as the lever. Regulate the rules to encourage and constrain; encourage the fair competition; strengthen the goal management; highlight the construction effects; construct the valuation system of the world-class universities and the subjects with Chinese characteristics to stimulate the vitality and the development activity in universities; lead the universities to achieve more progress.

Insist on the reform as the power. Deepen the comprehensive reform in the universities; accelerate the construction of modern university system with Chinese characteristics; strive to break the barriers of the system and the mechanism; speed up to construct the system and the mechanism with full of vitality and effects. More openness and useful to the development of the universities; take the lead in education and reform. [2]

\section{The Overall Goals}

Promote a series of universities and subjects with high level to reach the world' s level or come up to the advanced world level. Accelerate the modernization of the governance system and the governance capability in universities; improve the creation level in cultivating the talents, researching the science, serving the society and inheriting the culture, to make them become the important force in the discover of the knowledge and the creation of 
the science, the important source of the advanced ideology and the excellent culture, the important base of cultivating all kinds of high-quality and excellent talents. The universities should play an important role in supporting the development strategy of creation drive, serving the economic and the social development, advocating the excellent traditional culture of China, cultivating and practicing the core of socialism, promoting the development in the interior of the universities.

Up to the year 2020, a number of universities and subjects will reach the world' $\mathrm{s}$ level, and a series of subjects will reach $\mathrm{t}$ the advanced world level in the subjects.

Up to the year 2030, more and more universities and subjects will reach the world' $\mathrm{s}$ level, and a group of subjects will reach the advanced world level. The power of higher education will promote greatly on the whole.

Up to the middle years of the century, the quantities and the strength of the universities and subjects with the world-class will reach the advanced world level. The powerful country in education will be built.

\section{CONSTRUCTION TASK}

\section{A. Construct the World-Class Staff}

Firmly implement the strategy through the talents introduction; strengthen the support and lead roles of the high level talents; cultivate and introduce the world-class scientists, the discipline leaders and creation teams who are active in the international academic front and being needed by the great country strategy. The excellent talents should be attracted to gather in the universities.[3] Bide by the rules of the teachers growth; put the younger teachers and the creation teams as the emphasis; optimize the system environment of the younger teachers and let them stand out from the rest. We should accelerate the lasting development ability of the staff through the cultivation of the teams who are across-subject and across-disciplines. The university must pay attention to the teacher troop construction, strengthens the teacher's ethics and wind construction, cultivate and make the excellent teachers team who have the ideal and the belief, the moral sentiments, the rich knowledge and kind heart.

\section{B. Train the Top-Notch Innovative Talents}

Insist on taking high moral values establishment and people cultivation as the fundamental task of education; emphasize the key status of the talent cultivation. The university should cultivate the excellent talents who have the historical mission and social responsibility, creation spirit and practice ability with all kinds of creation, application and compound... Enforce the creation and pioneering education; greatly promote the personnel cultivation. [4] The university should promote the comprehensive quality of the students, international vision, science spirit and pioneering consciousness and creation ability. Reasonably promote the rate of pioneering in universities, lead the university graduate students to absorb themselves in the pioneering and group creation. The quality guarantee system should be perfect, putting the growth and the service of the students as the aim and outcome. The valuation system which is correct leading, science and effect, simple and clean should be set up in the universities to encourage the students to work harder and grow healthy.

\section{Promote the Scientific Research Level}

Put the great country need as the guide to promote the high level research ability, they should pay attention to contribution of the economy social development and the implementation of country strategy. Do something but not all; strengthen the top design of the subject and the strategy plan. [5] Especially we should construct the advantage subjects and domains which are the advanced in the country and the world-class in all the counties. We should promote the basic research level and keep up with the other countries or even surpass them in the international academic frontier. Research the problem of the strategy, the overall and the prospective. The university should cultivate the students to resolve the great problems and the original creation ability. [6] The science research organization should be created, and they should rely on the key research base and project to promote the creation ability of the science and the technology through the optimization of the resource and the coordinate creation. Promote the ability to serve the country decision through making the university thinking-tank with Chinese characteristics. The philosophy social science valuation and standard system should be built with Chinese characteristics, Chinese style and Chinese meaning.

Establish with Chinese characteristics, Chinese style, Chinese style of philosophy and social sciences academic evaluation and academic standard system. A strong academic atmosphere and free innovation environment should be created to protect the creation and failure and inspire the new vitality.

\section{Inherit and Create the Fine Culture}

Strengthen the construction of university culture; enforce the culture consciousness and system confidence to promote the progress of the society. The spirit and the culture of the world-class university with its characteristics should lead the development direction of the society civilization. The knowledge education should be lead under the values and the core values of socialism should be blending all the process in the teaching. The staff should be attracted to teach and research heart and soul. The students should be encouraged to work hard, cultivate the morality, argue reasonably and do honesty. Every university students should abide by the core values of socialism, and the excellent school trend, teaching trend and learning trend should be formed. The research and advocate towards the excellent traditional culture and core values of socialism should be enforced. We should inherit the essence of the traditional culture, avoid the bad and create to cultivate the offspring, promoting the social advanced culture construction.

\section{E. Promote the Transformation of the Fruits}

Deepen the melting of the industry and the education; combine the construction of the world-class universities and subjects with the development of the society closely. Improve the contribution rate of universities towards the transformation and upgrading. The university should become the birthplace of promoting the technology reform and accelerating creation drive. Promote the exchange of the subjects, talents and research in universities and 
industries. [7] Broad the basic research, application development, fruits transformation and industry lain. Promote the transformation system with market-oriented, the social capital join and many elements melting. Emphasize the connection of the science and the technology, creation project and realized production. We should promote the great science creation and key technology break through to change into the advanced production. The creation resource in universities should become the drive of the society.

\section{REFORM TASK}

\section{A. Enforce and Improve the Lead of the Party to the Universities}

Uphold and improve the president responsibility system under the leadership of the party committee, establish and improve the work system under the unified leadership of party committees, division and cooperation; change and improve the mechanism in universities. Further strengthen and improve the propaganda and ideological work in universities under the new situation; firmly grasp the ideological work leadership in universities; continuously determine the confidence of the road, the theory, and the system. [8] Comprehensively promote the party's construction in universities, strive to enlarge the coverage of the party organization, promote the work innovation. Effectiveness plays the role of fighting forts of the basic level party organizations in universities and the pioneer and model. Perfect the system to punish and avoid the corruption which accords with the universities and situation. Strictly implement the party's style to build a clean and responsible government system. The requirement that the party should be governed by the party must be carried out in every organization.

\section{B. Perfect the Internal Governance Structure}

To establish and perfect the articles of association universities, carrying out the mechanism to lead the association as the front which are perfect, regular and unified. Strengthen the construction of academic organization; Perfect the academic committee as the core of the academic management system and organizational structure, fully playing its roles in discipline construction, academic evaluation, academic development and study style construction. Improve the democratic management and supervision mechanism; expand the orderly participation, strengthen the consultation, fully playing the roles of the representatives of the teachers and the communist youth league and the student union in the democratic decision-making mechanism, actively exploring the making mechanism of the teachers and students on behalf of participation in school decision.

\section{Make Breakthrough in Crucial Links}

Promote the reform of cultivating the talents, and let the science and education cultivate the person together. Perfect the talent cultivation mechanism of innovation talented person under the support of high level research. Accelerate the reform of the personnel system. Actively improve the post Settings, classification management, performance evaluation, salary distribution and the rational flow of the talents. Increase the support to the talents. Accelerate reform of the mechanism of scientific research system. Make a bold attempt in the performance evaluation of scientific research security operation, fund raising, achievements, benefits treatment. We will accelerate the establishment of resource recruitment mechanism and make substantial progress in the struggle for social resources, expanding education force and funding channels.

\section{Construct the Social Participation Mechanism}

Insist on facing the society to run school independently, we will accelerate the establishment of a sound long-term mechanism with the social support and supervision. To establish and perfect the system of the council, the council's articles of association, and focus on enhancing the council's representative and authoritative, consultation, cooperation mechanism between the sound and the council members, fully playing the roles of the council to the reform, development and consultation, negotiation and deliberation, supervision, etc. To improve the cooperation and share the resource with the research institute and form the effective cooperation mechanism. Actively introduce specialized agencies to value the discipline of the school, majors, course level and quality.

\section{E. Promote the Cooperation and Exchange of Country}

Strengthen the substantial cooperation with world firstclass universities and academic institutions, the foreign high-quality education resources effective integration into the whole process of teaching and research, to conduct joint training high level talents and scientific research. Strengthen international collaborative innovation, and actively participate in the organization or international and regional major scientific planning and engineering. Create a favorable international environment for teaching and scientific research and enhance the appeal of foreign excellent teachers and high level students. Active participation in international education regulations, international education teaching evaluation and certification, enhance the international competitiveness of China's higher education and voice, to establish a good brand and image of the universities in China.

\section{SUPPORT MEASURES}

\section{A. Overall PLAN and Gradual Support}

Meeting the needs of economic and social development, based on the current situation of higher education development, having an overall plan towards the world first-class university and the first-class discipline construction, encourage and support the different types of high-level university subject differentiation development, speeding up into the world' s level or the advanced world level. Every five years as a cycle, the year of 2016 will be the first construction.

Universities should accord to their own actual, reasonably choose first-class university and the first-class discipline construction path, scientific planning, actively push forward. [9] Having a number of leading domestic, international frontier discipline of university high level, needing to build a first-class disciplines in many areas, forming a group of mutual support and coordinated development of the first-class discipline, comprehensive strength and international competitiveness in an all-round way, into a world top class universities or lists. Have a 
number of leading domestic and similar institutions are in advantage position in the international high level of the university, to optimize the main subject, strengthening school-running features, construction of a number of firstclass discipline, expand the international influence, promoting similar schools in the world top universities. Have a high level of the university, to highlight the subject advantages, enhance the level of discipline and world top or front to enter the field.

\section{B. Emphasize the Performance, Dynamical Support}

Innovation the way of financial support, pay more attention to the performance, form the incentive and constraints mechanism. The school quality especially discipline level will be considered when the capital allocation are doing, and the university with high level and characteristics will obtain more funds and supports. In the fair competition, the best, the strong and the characteristics will have a superior in obtaining the policy support. Perfect the management ways, let the financial department in universities have the right to control and arrange the funds, stimulating the universities to create the first and have their characteristics and vitality.

\section{All-Round Investment, Combined Support}

The building of world-class universities and subjects is a lasting task, which will need the efforts from all ways, such as the co-building mechanism under the cooperation of the government, the social and the universities, forming all-round investment and combined vitality.

Relevant departments and industries should be encouraged to participant the construction of the worldclass university and world-subject. They should tell the universities what talents they wanted and strengthen the cooperation with the universities. [10] They could support the building of the world-class university and worldsubject through co-operation, co-cultivation and co research.

\section{CONCLUSION}

According to the stable and gradual principle, the tuition in universities should be adjusted in different periods. We should explore the system of the university cost undertaking. The universities should expand the channels of financing, actively absorb the social donation, strengthen the cooperation with the society, and make the social support mechanism healthy to converge the resource. At the same time, there are some urgent problems in the key construction: such as taking advantage of its seniority, lacking of competition and repeating and overlapping which need enhancing the integration of the resource and creating the implementation ways. Some measures are formulated in order to summarize the experience, intensify the system plan, increase the reformation momentum, improve the boosting mechanism, insist doing contribution for the offspring, make overall construction considerations to build the world-class universities and the world-subjects and realize the historical great-leap forward development from the big country with higher education to the strong country with higher education.

\section{REFERENCES}

[1] A. Schubert, T. Braun. Relative indicators and relational chart for comparative assessment of publication output and citation impact [J]. Scientometrics. 1986 (5-6)

[2] Yuan Bentao, Pan Yilin, internalization and the construction of the world class universities: A case study in Tsing Hua University, Journal of Higher Education,[J]. Sep, 2009.

[3] Wang Yiqiu, What's Relied on to Construct the World-class Universities. Journal of Higher Education,[J]. Jan., 2011.

[4] Geng Youquan, the Strategy of World --class University Construction Model in America.[J]. Studies in Foreign Education. No. 10,2010

[5] Wang Shihua, the Ideology and Enlightenment of World-class universities[j]. China Higher Education Research, vol, 9, 2007.

[6] Zhou Guangli, the Characteristics of World-class Universities, [J]. China Higher Education Research, vol, 12, 2010.

[7] Zhang Hui. Dilemma and Beyond, on the World-class University Research Building [J]. Journa of Henan University (Social Science) Nov. 2013.

[8] Chen Zhili, Stepping from Big Country of Higher Education to Big Power of Higher Education. National Think Tank.

[9] Luo Yun, on the building of discipline in universities [J]. Journal of Higher Education,[J]. Jul., 2005.

[10] Li Huashu, on the University Disciplinary Construction [J]. Education Research. No. 4, 2006. 